\title{
Refolding of partially and fully denatured lysozymes
}

\author{
Jiun-Liang Lin · Ruoh-Chyu Ruaan • \\ Hsyue-Jen Hsieh
}

Received: 9 June 2006/ Revised: 4 January 2007 / Accepted: 8 January 2007 /

Published online: 20 February 2007

(C) Springer Science+Business Media B.V. 2007

\begin{abstract}
Lysozyme refolding with high yields sometimes results from incomplete denaturation. Dithiothreitol (DTT) is a reductant commonly used to reduce and unfold disulfide-stabilized lysozymes. Through the use of fluorescence spectroscopy to access the extent of denaturation, we found that the rate and extent of denaturation highly depended on the concentration of DTT. Further, the denaturation exhibited a two-phase transition at a high DTT concentration with DTT at $>100 \mathrm{mM}$ and long denaturation time $(>24 \mathrm{~h})$ being needed for complete denaturation. A low DTT concentration and a short denaturation time resulted in fast refolding with high activity recovery, while a high DTT concentration and a long denaturation time resulted in slow refolding with low activity recovery. Hence, the renaturation of disulfide-containing lysozyme was highly affected by the extent of denaturation.
\end{abstract}

J.-L. Lin · H.-J. Hsieh ( $ه)$

Department of Chemical Engineering, National

Taiwan University, Taipei, Taiwan

e-mail: hjhsieh@ntu.edu.tw

R.-C. Ruaan

Department of Chemical and Materials Engineering, National Central University, Jhongli, Taiwan

R.-C. Ruaan

R\&D Center of Membrane Technology, Chung Yuan University, Jhongli, Taiwan
Keywords Denaturation · Disulfide bonds · Lysozyme $\cdot$ Refolding

\section{Introduction}

Production of foreign recombinant proteins often results in the formation of inclusion bodies from which protein recovery and renaturation are critical steps. To demonstrate the effectiveness of refolding methods, denatured proteins are often obtained by purposely unfolding native ones. The yield of the refolded protein can then be easily calculated.

Denaturation of native proteins containing no disulfide bonds is a process by which hydrophobic interactions and hydrogen bonds are destabilized. An excess amount of a chaotropic agent, such as guanidine hydrochloride or urea, is added to disrupt these interactions (Terashima and Suzuki 1995). However, some proteins, such as lysozyme, are further stabilized by disulfide bonds. There are four disulfide bonds stabilizing the conformation of hen egg white lysozyme and the use of a chaotropic agent alone is incapable of denaturing it. Therefore, a reducing agent such as dithiothreitol (DTT) or mercaptoethanol is usually used together with the chaotropic agent to unfold disulfide bond-stabilized proteins. The extent and rate of unfolding/denaturation are determined by the concentration of the reducing agent, which 
also affects the subsequent refolding process. Many refolding studies do not clearly report the final state of the unfolded protein. As shown in Table 1, the denaturation conditions in the literature are seldom the same, implying that partially unfolded proteins might have been used in some refolding studies, and thus the effectiveness of the refolding method is still unknown for fully denatured proteins.

We therefore attempted to investigate the effect of partial unfolding/denaturation on lysozyme refolding. The extent of unfolding needs to first be characterized. However, the presence of DTT results in very high absorbance that masks the protein ellipticity and thus hinders the determination of unfolding by circular dichroism (Panda and Horowitz 2000). So, only the intrinsic fluorescence spectrum of tryptophan has been adopted to represent the extent of protein denaturation (Touch et al. 2004). When proteins are exposed to a chaotropic reagent, tryptophans in the inner hydrophobic moiety are exposed to the bulk solution, and a red shift in the wavelength at the maximum emission intensity is often observed (Copeland 1993; Ladokhin 2000).

A direct dilution method is used to refold the lysozyme. In addition, a low concentration of a chaotropic agent is used to prevent the aggregation of partially folded proteins and to subsequently improve the refolding yield (Lanckriet and Middelberg 2004). The optimum ratio of reduced glutathione (GSH) to oxidized glutathione (GSSG) varies as the amount of residual DTT varies (Raman and Ramakrishna 1996). Hence, the GSH/GSSG ratio in the presence of DTT is critical. Our results indicated that activity recovery, even for fully reduced/denatured lysozyme, can be improved by up to $80-90 \%$ under optimal conditions.

\section{Materials and methods}

Materials

Hen egg white lysozyme (EC 3.2.1.17, MW: $14.5 \mathrm{kDa}, 42,500$ units $/ \mathrm{mg}$ ) and dried cells of Micrococcus lysodeikticus were purchased from Sigma. Other chemicals used throughout this study were of reagent grade.

Enzyme activity assays

Lysozyme activity was determined by the rate of lysis of Micrococcus lysodeikticus cells. A lysozyme solution $(0.12 \mathrm{ml})$ was added to a suspension $(0.63 \mathrm{ml})$ of $M$. lysodeikticus $(0.4 \mathrm{mg} / \mathrm{ml})$ in $50 \mathrm{mM}$ phosphate buffer ( $\mathrm{pH} 7.0)$. The decrease in turbidity was monitored at $450 \mathrm{~nm}\left(\mathrm{OD}_{450}\right)$ at $25^{\circ} \mathrm{C}$ over several minutes. Lysozyme activity was calculated from the slope of the curve of $\mathrm{OD}_{450}$ vs. time in the linear range. One unit of lysozyme activity produced a decrease in $\mathrm{OD}_{450}$ of 0.003467/min (1 cm light path).

\section{Protein denaturing}

Various amounts of dithiothreitol (DTT) were added to the denaturing buffer $(8 \mathrm{M}$ urea, $0.2 \mathrm{M}$ $\mathrm{NaCl}, 1 \mathrm{mM}$ EDTA, and $0.1 \mathrm{M}$ Tris/HCl; $\mathrm{pH}$ 8.3) to denature the lysozyme. The extent of denaturation was monitored by the intrinsic fluorescence of tryptophan. The excitation wavelength was

Table 1 Conditions for lysozyme unfolding

\begin{tabular}{lllllr}
\hline References & $\begin{array}{l}\text { Lysozyme } \\
(\mathrm{mg} / \mathrm{ml})\end{array}$ & Denaturant & DTT (mM) & Buffer & Unfolding time (h) \\
\hline Chang and Liu (2006) & 5 & $8 \mathrm{M}$ urea & 10 & $0.1 \mathrm{M}$ Tris, pH 8.6 & 24 \\
Katoh and Katoh (2000) & $5-35$ & $8 \mathrm{M}$ urea & 10 & $0.1 \mathrm{M}$ Tris, pH 8.5 & 2 \\
Dong and Wang (2002) & $30-80$ & $8 \mathrm{M}$ urea & 30 & $0.1 \mathrm{M}$ Tris, pH 8.5 & 1.33 \\
Lu et al. (2005; Lu and Zhang 2006) & 50 & $8 \mathrm{M}$ urea & 30 & $0.1 \mathrm{M}$ Tris, pH 8.6 & 3 \\
Buswell and Middelberg (2002) & $3-25$ & $8 \mathrm{M}$ urea & 32 & $0.05 \mathrm{M} \mathrm{Tris,} \mathrm{pH} \mathrm{8.0}$ & 1 \\
Li and Liu (2004) & 10 & $6 \mathrm{M} \mathrm{Gdn/HCl}$ & 150 & $0.1 \mathrm{M}$ Tris, pH 8.6 & 3 \\
Shimizu and Fujimoto (2000) & 20 & $6 \mathrm{M} \mathrm{Gdn} / \mathrm{HCl}$ & 150 & $0.1 \mathrm{M}$ Tris, pH 8.6 & 15 \\
Batas and Chaudhuri (1995) & $10-80$ & $8 \mathrm{M}$ urea & 150 & $0.1 \mathrm{M}$ Tris, pH 8.6 & 2 \\
Gu and Su (2001) & $2.6-30$ & $8 \mathrm{M}$ urea & 200 & $0.1 \mathrm{M}$ Tris, pH 8.7 & $4-5$ \\
\hline
\end{tabular}


$280 \mathrm{~nm}$, and the emission spectrum from 300 to $400 \mathrm{~nm}$ was recorded to determine the wavelength of the maximum emission and the red-shift.

Effects of the concentration of oxidized glutathione (GSSG) on lysozyme refolding

Fully reduced/denatured lysozyme $(1 \mathrm{mg} / \mathrm{ml})$ was obtained by incubating the lysozyme in a denaturing buffer containing $40 \mathrm{mM}$ DTT for more than $30 \mathrm{~h}$. The fully denatured lysozyme was then reactivated by 100 -fold dilution in the refolding buffer (1 mM EDTA and 0.1 M Tris/HCl; pH 8.3) containing various amounts of GSSG.

Effects of partial unfolding/denaturation on protein refolding

Partially denatured lysozyme $(5 \mathrm{mg} / \mathrm{ml})$ was obtained either by $30 \mathrm{~h}$ of reduction in denaturing buffers containing various amounts of DTT, or by incubation in $0.2 \mathrm{M}$ DTT denaturing buffer for various lengths of time. The partially denatured lysozyme was refolded by a 50 -fold dilution in the refolding buffer, and the refolding processes were monitored by the blue shift in the wavelength at the maximum emission intensity.

\section{Results and discussion}

Denaturation of lysozyme

\section{Lysozyme was not unfolded by urea alone}

Native and urea-treated lysozymes were monitored by the intrinsic fluorescence of tryptophans in the protein, as shown in Fig. 1(a). Native lysozyme had been stored in a Tris/ $\mathrm{HCl}$ buffer (0.1 or $1 \mathrm{mM}$ EDTA; $\mathrm{pH} 8.3$ ) for $24 \mathrm{~h}$, and the wavelength at maximum emission intensity $\left(\lambda_{\max }\right)$ was $341.2 \mathrm{~nm}$. Urea-treated lysozyme, incubated in another Tris/ $\mathrm{HCl}$ buffer plus $8 \mathrm{M}$ urea and $0.2 \mathrm{M} \mathrm{NaCl}$ for $24 \mathrm{~h}$, had a $\lambda_{\max }$ of $339.2 \mathrm{~nm}$ showing that $8 \mathrm{M}$ urea did not disrupt the tertiary structure of the lysozyme.

Fully unfolded lysozyme could only be obtained after DTT was added to the urea-treated sample (0.01 mg protein $/ \mathrm{ml})$. As shown in Fig. 1(b), the
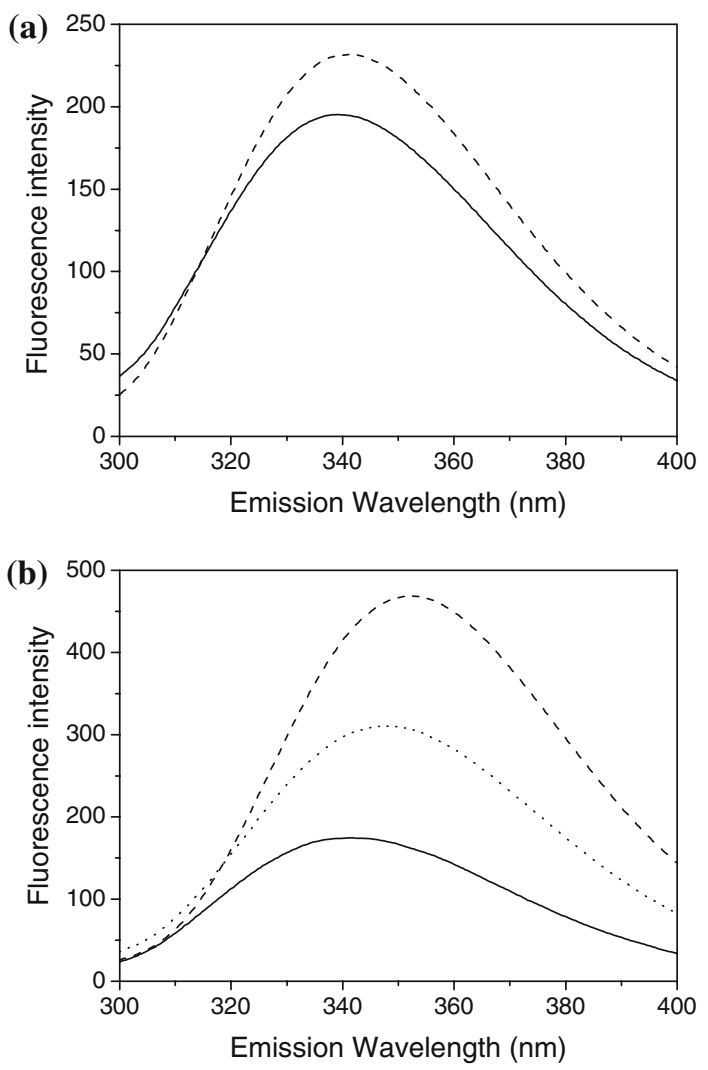

Fig. 1 Fluorescence spectrum of $0.01 \mathrm{mg}$ lysozyme $/ \mathrm{ml}$. (a) Native lysozyme (- - ) freshly prepared in $0.1 \mathrm{M}(\mathrm{pH} 8.3)$ Tris buffer containing $1 \mathrm{mM}$ EDTA, $\lambda_{\max }=341.2 \mathrm{~nm}$. Urea-treated lysozyme (-) denatured in denaturing buffer for $1 \mathrm{~h}, \lambda_{\max }=339.2 \mathrm{~nm}$. (b) Lysozyme incubated for $1 \mathrm{~min}(-)$ with $\lambda_{\max }=342.4 \mathrm{~nm}, 4 \mathrm{~h} \mathrm{(--)}$ with $\lambda_{\max }=348 \mathrm{~nm}, 24 \mathrm{~h}(\cdots)$ with $\lambda_{\max }=352 \mathrm{~nm}$ in denaturing buffer containing $1 \mathrm{mM}$ DTT. The denaturing buffer contained $8 \mathrm{M}$ urea, $0.2 \mathrm{M} \mathrm{NaCl}$, and $1 \mathrm{mM}$ EDTA in $0.1 \mathrm{M}(\mathrm{pH} 8.3)$ Tris buffer

$\lambda_{\max }$ shifted to a longer wavelength as the incubation time increased. The $\lambda_{\max }$ of fully denatured lysozyme was $352 \mathrm{~nm}$. The fully unfolded lysozyme not only had a longer $\lambda_{\max }$ wavelength, but also had a higher emission intensity than the native and urea-treated lysozymes. The results confirmed that the disulfide bonds are critical for stabilizing lysozymes (Touch et al. 2004).

Effect of the concentration of DTT on lysozyme unfolding

By monitoring the unfolding process through the fluorescence spectrum of a $0.01 \mathrm{mg} / \mathrm{ml}$ lysozyme 
solution, the unfolding rate strongly depended on the concentration of DTT. In Fig. 2(a), when lysozyme was denatured in a buffer containing $8 \mathrm{M}$ urea and $2.8 \mu \mathrm{M}$ DTT, the peak of the fluorescence spectrum, $\lambda_{\max }$, shifted only slightly even after $30 \mathrm{~h}$ of incubation. As the concentration of DTT increased to $0.2 \mathrm{mM}$, lysozyme rapidly unfolded with a $\lambda_{\max }$ of $348 \mathrm{~nm}$ and then slowly underwent a second phase of unfolding to $\lambda_{\max }$ of $352 \mathrm{~nm}$. At DTT concentrations higher than $10 \mathrm{mM}$, lysozyme rapidly unfolded to the final state of $\lambda_{\max }=352 \mathrm{~nm}$ (Fig. 2).

The unfolding rate was also dependent on the lysozyme concentration. With lysozyme at $5 \mathrm{mg} / \mathrm{ml}$, two-phase unfolding was observed at DTT above
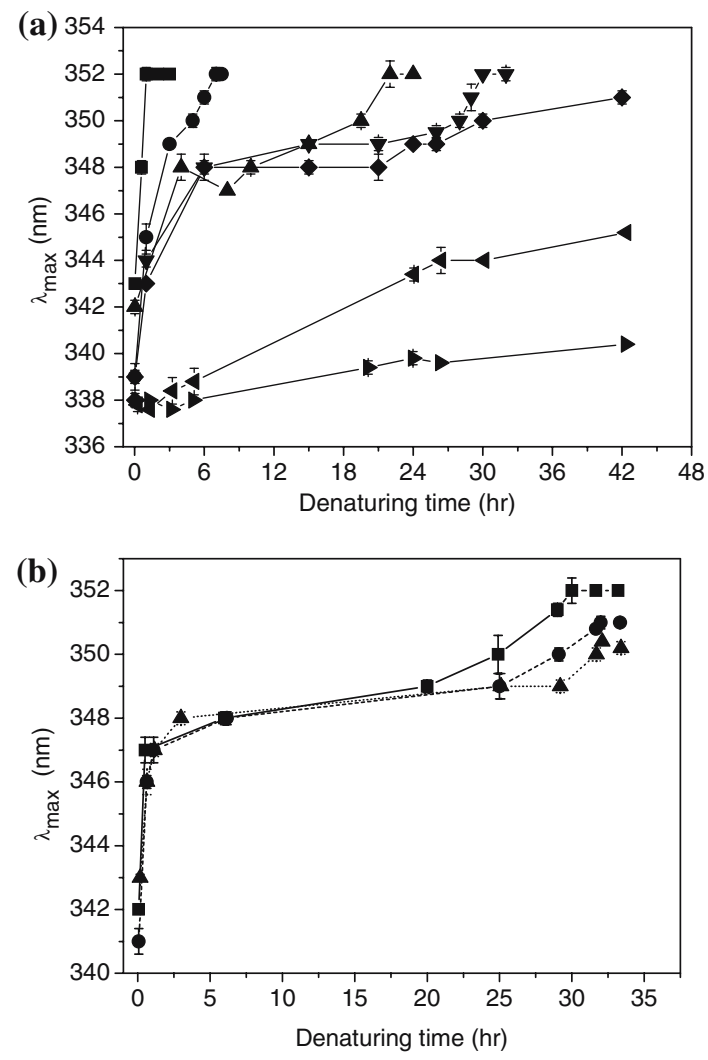

Fig. 2 Extent of denaturation of lysozyme. (a) Lysozyme at $0.01 \mathrm{mg} / \mathrm{ml}$ was denatured in denaturing buffer containing $10(\mathbf{\square}), 4(\bullet), 1(\boldsymbol{\Delta}), 0.4(\boldsymbol{\nabla}), 0.2(\bullet), 0.014(\boldsymbol{\bullet})$, and 0.0028 ( $\mathrm{mM}$ DTT. (b) Lysozyme at $5 \mathrm{mg} / \mathrm{ml}$ was denatured in $8 \mathrm{M}$ urea denaturing buffer containing 0.2 $(\boldsymbol{\bullet}), 0.1(\bullet)$, and $0.031(\boldsymbol{\Delta})$ M DTT. The denaturation was monitored by the $\lambda_{\max }$ of intrinsic fluorescence of tryptophan residues of lysozyme $(n=3)$
$10 \mathrm{mM}$ (Fig. 2b). The rates of the first phase of unfolding were similar when lysozyme $(5 \mathrm{mg} / \mathrm{ml})$ was incubated in 30, 100, and $200 \mathrm{mM}$ DTT. The concentration of DTT affected only the rate of the second phase of unfolding.

Optimization of lysozyme refolding by direct dilution

Effect of the concentration of GSSG on lysozyme refolding

The GSH/GSSG ratio is critical for refolding disulfide bond-containing proteins. As the residual DTT from the denatured lysozyme solution could function as a reducing agent, like GSH, only oxidized glutathione (GSSG) was needed for lysozyme refolding. The oxidoreductive factor $(\alpha)$, defined as the molar ratio of GSSG to DTT, was used to evaluate its effect on lysozyme refolding. A small amount of residual chaotropic agent was beneficial to protein refolding. A low concentration of guanidinium hydrochloride or urea prevented aggregate formation during protein refolding $(\mathrm{Gu}$ and $\mathrm{Su} 2001)$. Our results indicated that the addition of $1.5 \mathrm{M}$ urea to the refolding buffer significantly decreased the amount of lysozyme aggregates (data not shown). So, the effect of the GSSG concentration on the refolding yield is shown in Fig. 3 with the addition of $1.5 \mathrm{M}$ urea to the refolding buffer.

The fully reduced/denatured lysozyme was more difficult to refold than partially denatured lysozyme in most other research because a higher GSSG concentration was needed to overcome the influence of the residual DTT and to re-form the reduced disulfide bonds. When the concentration of GSSG was lower than the residual concentration of DTT $(\alpha<1)$, there was almost no recovery of lysozyme activity, even after being refolded for $3 \mathrm{~h}$. When increasing the value of $\alpha$, the refolding rate and activity recovery also increased. Our results are similar to those reported by Raman and Ramakrishna (1996) but differ from results obtained by Hevehan and Clark (1996). Our results showed that low-activity recovery was obtained when $\alpha$ was less than 1 and the recovery increased with increasing $\alpha$. However, Hevehan and Clark (1996) reported that the refolding yield 


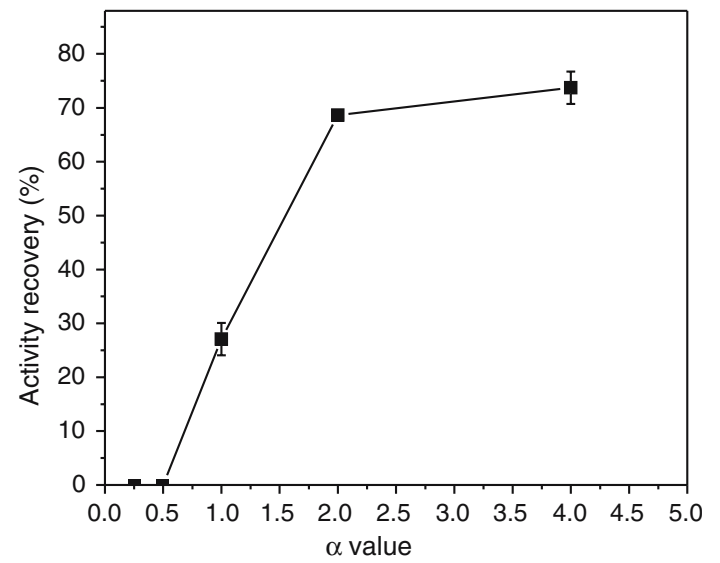

Fig. 3 Effect of the oxidized glutathione (GSSG) concentration added to the refolding buffer on activity recovery. Fully reduced/denatured lysozyme was refolded by a 50 fold dilution (at $0.1 \mathrm{mg} / \mathrm{ml})$ in $0.1 \mathrm{M}(\mathrm{pH} \mathrm{8.3)}$ Tris buffer containing $1.5 \mathrm{M}$ urea and $1 \mathrm{mM}$ EDTA, with different $\alpha$ values $(\alpha=$ molar ratio of GSSG to DTT) in $0.1 \mathrm{M}(\mathrm{pH}$ 8.3) Tris buffer for $3 \mathrm{~h}$. The specific activity of native lysozyme (100\% activity) was 42,500 units $/ \mathrm{mg}$ ). The mass recovery was determined by the protein absorbance at $280 \mathrm{~nm}$, and all values were between $95 \%$ and $97 \%(n=3)$

did not increase with an increasing amount of GSSG. On the contrary, the results reported by Raman and Ramakrishna (1996) were similar to ours. Our data indicated that an $\alpha$ value equal to 2 was sufficient for the oxidative refolding of lysozyme (data not shown).

\section{Effect of incomplete denaturation on lysozyme refolding}

Many instances of superior refolding might have resulted from incomplete unfolding, which resulted from either a low amount of reducing agent or a short unfolding time. We examined the possible effects of incomplete denaturation on subsequent refolding by denaturing lysozyme at different DTT concentrations and for different denaturation times. The refolding of lysozyme was carried out under the obtained optimal conditions: urea at $1.5 \mathrm{M}$ and an $\alpha$ value of 2 . The rate and yield of refolding were monitored by fluorescence spectroscopy and an activity assay. Lysozyme at $5 \mathrm{mg} / \mathrm{ml}$ was denatured in denaturing buffer containing 1.5, 7, 35, or $200 \mathrm{mM}$ DTT for $30 \mathrm{~h}$. The unfolded protein was then refolded
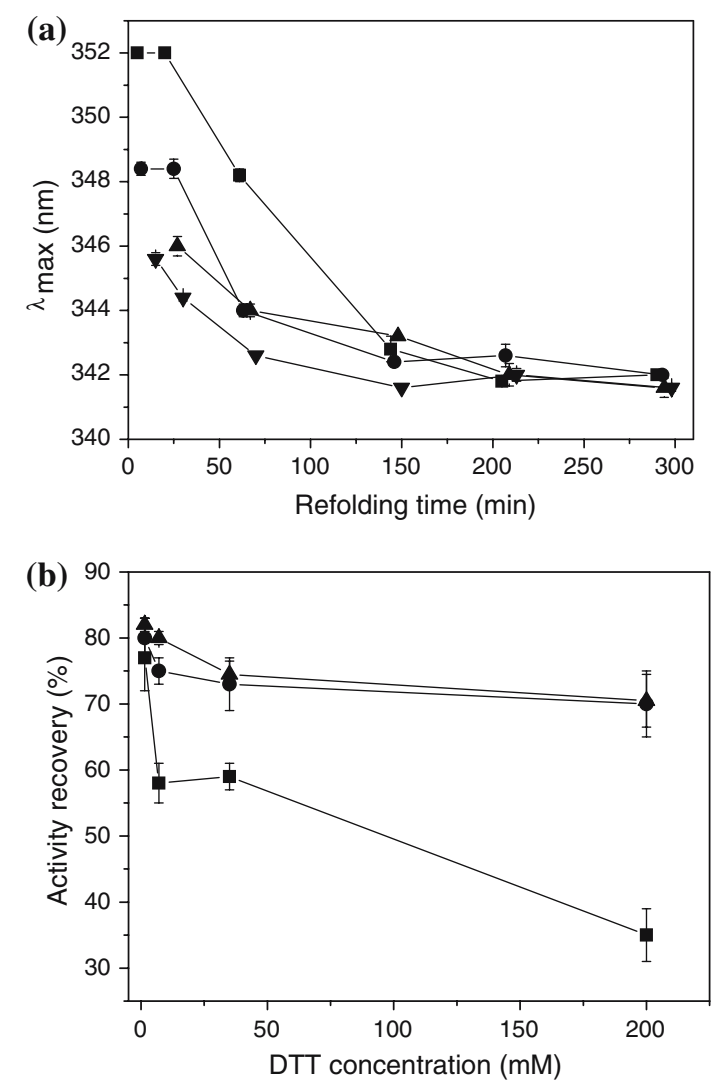

Fig. 4 Effect of partial denaturation on lysozyme refolding. Lysozyme $(5 \mathrm{mg} / \mathrm{ml})$ was denatured in denaturing buffer containing different DTT concentrations for $30 \mathrm{~h}$ and were refolded by a 50-fold dilution of refolding buffer $(\alpha=2)$ containing $1.5 \mathrm{M}$ urea. (a) Refolding process of lysozymes with different extents of denaturation caused by different DTT concentrations: $200(\boldsymbol{\bullet}), 35(\bullet), 7(\boldsymbol{\Delta})$, and $1.5(\boldsymbol{\nabla}) \mathrm{mM}$ DTT, monitored by the blue-shift of $\lambda_{\max }$ in the fluorescence spectrum (with excitation at $280 \mathrm{~nm}$ ). (b) Activity recovery of lysozymes with different extents of denaturation over time: $100(\boldsymbol{\bullet}), 220(\bullet)$, and $320(\boldsymbol{\Delta}) \mathrm{min}$. The specific activity of native lysozyme (100\% activity) was 42,500 units $/ \mathrm{mg}$ ). The mass recovery was determined by protein absorbance at $280 \mathrm{~nm}$, and all values were between $95 \%$ and $97 \%(n=3)$

by a 50 -fold dilution. As shown in Fig. 4(a), at the beginning, the lysozyme was completely reduced/ denatured by $200 \mathrm{mM}$ DTT and had a $\lambda_{\max }$ of $352 \mathrm{~nm}$ in the fluorescent spectrum, and the lysozyme, partially denatured by $1.5,7$, or $35 \mathrm{mM}$ DTT, had a $\lambda_{\max }$ of $346-348 \mathrm{~nm}$. As shown in Fig. 4(b), the fully unfolded lysozyme slowly refolded toward the native state, but the partially unfolded lysozyme had faster refolding rates. 
Partially unfolded lysozyme was also obtained by varying the unfolding time. Lysozyme at $5 \mathrm{mg} / \mathrm{ml}$ was incubated in a buffer containing $200 \mathrm{mM}$ DTT for different times. The refolding of lysozyme was also carried out at a urea concentration of $1.5 \mathrm{M}$ and an $\alpha$ value of 2 . As shown in Fig. 5(a), the $\lambda_{\max }$ in the fluorescent spectrum of the fully unfolded lysozyme (those being denatured for $30 \mathrm{~h}$ ) returned slowly to the native state with a $\lambda_{\max }$ of $341 \mathrm{~nm}$. The lysozyme in the intermediate state (those being denatured for $8 \mathrm{~h}$ )
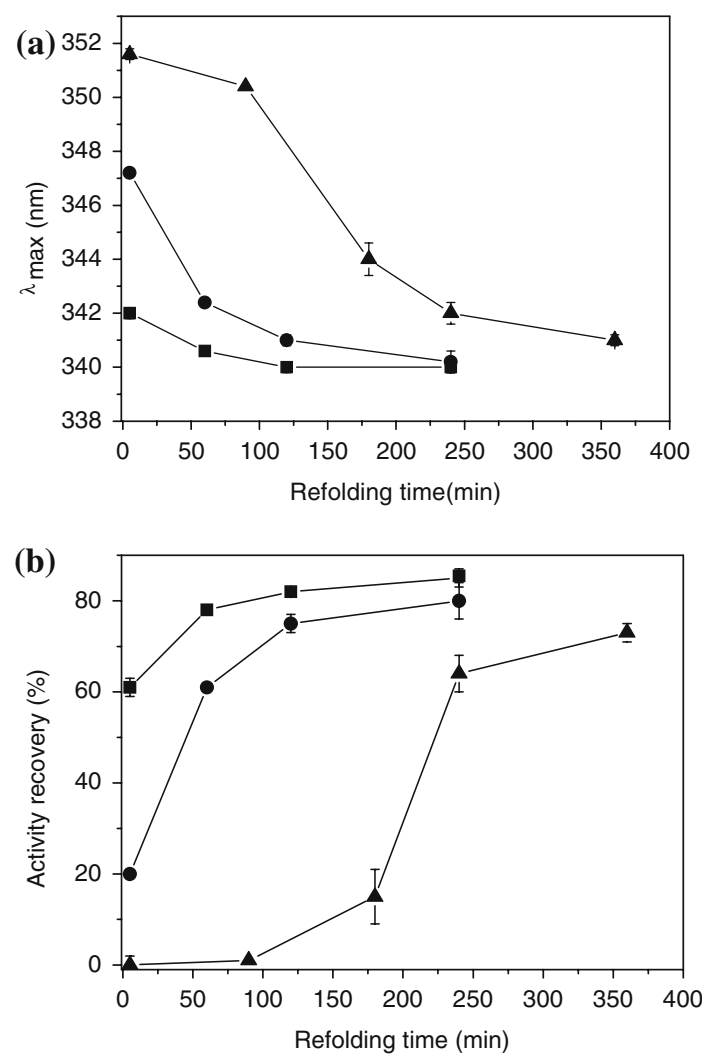

Fig. 5 Effect of partial denaturation on lysozyme refolding. Lysozyme $(5 \mathrm{mg} / \mathrm{ml})$ was denatured in $8 \mathrm{M}$ urea and $200 \mathrm{mM}$ DTT denaturing buffer for different lengths of time: $1(\boldsymbol{\bullet}), 8(\bullet)$, and $30(\boldsymbol{\Delta}) \mathrm{h}$ and then refolded by a 50 fold direct dilution in refolding buffer $(\alpha=2)$ containing $1.5 \mathrm{M}$ urea. (a) Refolding process of lysozymes with different extents of denaturation caused by varying denaturing times and monitored by the blue-shift of $\lambda_{\max }$ in the fluorescence spectrum (with excitation at $280 \mathrm{~nm}$ ). (b) Activity recovery of lysozymes with different extents of denaturation over time. The specific activity of native lysozyme ( $100 \%$ activity) was 42,500 units $/ \mathrm{mg}$. The mass recovery was determined by the protein absorbance at $280 \mathrm{~nm}$, and all values were between $95 \%$ and $97 \%(n=3)$ refolded much faster, and slightly denatured lysozyme (those being denatured for $1 \mathrm{~h}$ ) rapidly returned to the native state. The activity assay showed similar behaviors. As shown in Fig. 5(b), $80 \%$ activity recovery could easily be achieved if the lysozyme had been exposed to the unfolding buffer for only $1 \mathrm{~h}$. But it took $4 \mathrm{~h}$ for the fully unfolded sample to recover $60 \%$ of its activity.

\section{Conclusions}

Many refolding methods have been proposed to efficiently renature proteins to their native state. However, the state of the unfolded protein has not been carefully examined. Partially unfolded proteins can easily be refolded with high activity recovery. But the refolding of fully unfolded proteins is much more difficult. Our studies showed that it requires a high concentration of a reducing agent and a long incubation time to fully denature lysozyme. The amount of the reducing agent needed to fully unfold lysozyme is also dependent on the protein concentration. Further, lysozyme in a partially unfolded intermediate state might be obtained before undergoing refolding. The effectiveness of refolding methods might be misjudged if the unfolded state has not been clearly characterized.

Acknowledgements This study was financially supported by the National Science Council, Taiwan (NSC94-2214-E-008-002 and NSC93-2214-E-002-034) and the Center-of-Excellence Program on Membrane Technology, the Ministry of Education, Taiwan.

\section{References}

Batas B, Chaudhuri JB (1995) Protein refolding at high concentration using size-exclusion chromatography. Biotechnol Bioeng 50:1-23

Buswell AM, Middelberg APJ (2002) Critical analysis of lysozyme refolding kinetics. Biotechnol Prog 18:470475

Chang CK, Liu HS (2006) Step change of mobile phase flow rate to enhance protein folding in size exclusion chromatography. Biochem Eng J 29:2-11

Copeland RA (1993) Methods for protein analysis: a practical guide to laboratory protocols. Chapman and Hall, New York

Dong XY, Wang Y (2002) Size exclusion chromatography with an artificial chaperone system enhanced 
lysozyme renaturation. Enzyme Microb Technol 30:792-797

Gu Z, Su Z (2001) Urea gradient size-exclusion chromatography enhanced the yield of lysozyme refolding. J Chromatogr A 918:311-318

Hevehan DL, Clark EDB (1996) Oxidative renaturation of lysozyme at high concentration. Biotechnol Bioeng 54:221-230

Katoh S, Katoh Y (2000) Continuous refolding of lysozyme with fed-batch addition of denatured protein solution. Process Biochem 35:1119-1124

Ladokhin AS (2000) Fluorescence spectroscopy in peptide and protein analysis. In: Meyers RA (ed) Encyclopedia of analytical chemistry: applications, theory, and instrumentation. John Wiley \& Sons, pp 5762-5779

Lanckriet H, Middelberg APJ (2004) Continuous chromatographic protein refolding. J Chromatogra A 1022:103-113

Li JJ, Liu YD (2004) Hydrophobic interaction chromatography correctly refolding proteins assisted by glycerol and urea gradient. J Chromatogr A 1061:193-199

Lu D, Zhang M (2005) The mechanism of PNIPAAmassisted refolding of lysozyme denatured by urea. Biochem Eng J 24:55-64
Lu D, Wang J, Liu Z (2005) How CTAB assists the refolding of native and recombinant lysozyme. Biochem Eng J 24:267-277

Lu D, Zhang M (2006) Dextran-grafted-PNIPAAm as an artificial chaperone for protein refolding. Biochem Eng J 27:226-343

Panda M, Horowitz PM (2000) Active-site sulfhydryl chemistry plays a major role in the misfolding of urea-denatured rhodanese. J Protein Chem 19:399409

Raman B, Ramakrishna T (1996) Refolding of denatured and denatured/reduced lysozyme at high concentrations. J Biol Chem 271:17067-17072

Shimizu H, Fujimoto K (2000) Improved refolding of denatured/reduced lysozyme using disulfide-carrying polymeric microspheres. Colloids Surf B 18:137-144

Terashima M, Suzuki K (1995) Effective refolding of fully reduced lysozyme with a flow-type reactor. Process Biochem 31:341-345

Touch V, Hayakawa S, Saitoh K (2004) Relationships between conformational changes and antimicrobial activity of lysozyme upon reduction of its disulfide bonds. Food Chem 84:421-428 